\title{
Altered miRNA-4321 expression in maternal and foetal placenta of intrauterine growth restricted bovine foetuses
}

\author{
Rutkowska, Karolina ; Stachowiak, Monika ; Oprzadek, Jolanta ; Bauersachs, Stefan ; Flisikowski, \\ Krzysztof
}

\begin{abstract}
Intrauterine growth restriction (IUGR) is a serious pregnancy complication caused by placental insufficiency. We previously reported that truncation of MIMT1 gene exons 3 and 4 (MIMT1Del) causes IUGR in cattle. Here we investigated miRNA expression in the foetal and maternal placenta tissues of MIMT1Del/WT foetuses. Small RNA next generation sequencing and quantitative PCR revealed placental tissue-specific expression of the miR-4321, known to regulate many genes involved in early foetal development. This study also indicated that maternal and foetal components of the placenta respond differently to a deleterious conceptus mutation.
\end{abstract}

DOI: https://doi.org/10.1016/j.placenta.2018.09.004

Posted at the Zurich Open Repository and Archive, University of Zurich

ZORA URL: https://doi.org/10.5167/uzh-157374

Journal Article

Accepted Version

Originally published at:

Rutkowska, Karolina; Stachowiak, Monika; Oprzadek, Jolanta; Bauersachs, Stefan; Flisikowski, Krzysztof (2018). Altered miRNA-4321 expression in maternal and foetal placenta of intrauterine growth restricted bovine foetuses. Placenta, 70:50-52.

DOI: https://doi.org/10.1016/j.placenta.2018.09.004 


\section{Accepted Manuscript}

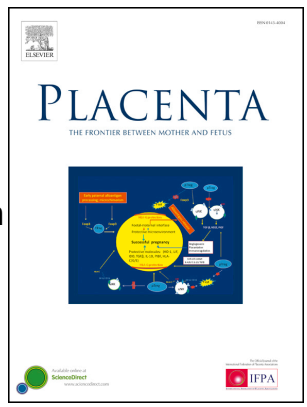

Karolina Rutkowska, Monika Stachowiak, Jolanta Oprzadek, Stefan Bauersachs, Krzysztof Flisikowski

Altered miRNA-4321 expression in maternal and foetal placenta of intrauterine growth restricted bovine foetuses

PII: S0143-4004(18)30631-3

DOI: $\quad$ 10.1016/j.placenta.2018.09.004

Reference: $\quad$ YPLAC 3876

To appear in: Placenta

Received Date: 26 June 2018

Revised Date: 7 September 2018

Please cite this article as: Rutkowska K, Stachowiak M, Oprzadek J, Bauersachs S, Flisikowski K, Altered miRNA-4321 expression in maternal and foetal placenta of intrauterine growth restricted bovine foetuses, Placenta (2018), doi: https://doi.org/10.1016/j.placenta.2018.09.004.

This is a PDF file of an unedited manuscript that has been accepted for publication. As a service to our customers we are providing this early version of the manuscript. The manuscript will undergo copyediting, typesetting, and review of the resulting proof before it is published in its final form. Please note that during the production process errors may be discovered which could affect the content, and all legal disclaimers that apply to the journal pertain. 
1

2

3

4 Karolina Rutkowska1, Monika Stachowiak², Jolanta Oprzadek ${ }^{1}$, Stefan Bauersachs ${ }^{3}$, 5 Krzysztof Flisikowski ${ }^{4}$

6

7

8

9

10

Short communication

\section{Altered miRNA-4321 expression in maternal and foetal placenta of intrauterine growth} restricted bovine foetuses.

1. Institute of Genetics and Animal Breeding of the Polish Academy of Sciences, 05-552 Jastrzebiec, Postepu 36a, Poland

2. Department of Genetics and Animal Breeding, Poznan University of Life Sciences, Wolynska 33, 60-637 Poznan, Poland.

3. Clinic for Animal Reproduction Medicine, Genetics and Functional Genomics Group, University of Zurich, Tannenstrasse 1, CH-8092 Zurich, Switzerland

4. Chair of Livestock Biotechnology, Technische Universität München, Liesel-Beckmann str. 1, 85354 Freising, Germany.

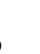

16

17

8

(1)

(1)

Corresponding author:

Dr. Krzysztof Flisikowski

Chair of Livestock Biotechnology

Technical University in Munich

Liesel-Beckmann-Straße 1

85354 Freising

Tel.: +49 8161 71-2036

2 Fax: +49 8161 71-2108

33 Email: flisikowski@wzw.tum.de 
1 Abstract

2 Intrauterine growth restriction (IUGR) is a serious pregnancy complication caused by 3 placental insufficiency. We previously reported that truncation of MIMT1 gene exons 3 and 4 $4 \quad\left(M I M T 1^{D e l}\right)$ causes IUGR in cattle. Here we investigated miRNA expression in the foetal and 5 maternal placenta tissues of $M I M T 1^{D e / W T}$ foetuses. Small RNA next generation sequencing 6 and quantitative PCR revealed placental tissue-specific expression of the miR-4321, known 7 to regulate many genes involved in early foetal development. This study also indicated that 8 maternal and foetal components of the placenta respond differently to a deleterious 9 conceptus mutation.

Key words: bovine foetal growth restriction, miRNA expression, placenta, mammals 


\section{Introduction}

Intrauterine growth restriction (IUGR) is a major problem in both human [1] and animal [2] pregnancies responsible for perinatal mortality and morbidity [3] and ill health in later life [4].

The placenta is a heterocellular structure composed of foetal and maternal cells that creates an interface between mother and foetus. Balanced communication between placental cells is crucial for proper foetal development [5]. We previously reported that truncation of exons 3 and 4 of the MIMT1 gene (MER1 repeat containing imprinted transcript 1) causes IUGR and late abortion in Ayrshire cattle [6]. We also showed that maternal placental tissues affect the penetrance of the paternally inherited mutation [7].

miRNAs are important in embryo development in human, mice and cattle [8-10], and altered expression has been implicated in several pregnancy complications [11], including intrauterine growth restriction [12]. Blocking the production of maternally inherited miRNAs by inactivation of Dicer in maturing oocytes resulted in IUGR [13], suggesting that foetal miRNAs play an important role in placental development and function, possibly via communication between the foetal and maternal placenta.

The aim of this study was to examine miRNA expression in the foetal and maternal placenta tissues of intrauterine growth restricted bovine foetuses.

\section{Methods}

\section{$2.1 \quad$ Ethics statement}

All experimental procedures involving animals were conducted in accordance with ethical standards approved by the Animal Ethics Committee of the State Provincial Office of Southern Finland (ESAVI-2010-08583/YM-230). Insemination and tissue sampling were carried out by standard veterinary protocols according to European Union Normative for Care and Use of Experimental Animals.

\section{$2.2 \quad$ Tissue samples}

Maternal and foetal placenta samples were collected from cows gestating $M I M T 1^{D e / W T}$ foetuses and cows gestating wild-type foetuses terminated on the $94^{\text {th }} \pm 12$ day of pregnancy, as described earlier [7]. All foetuses were gestated in wild-type cows and all were fathered by the same $M I M T 1^{\text {DelWT }}$ sire. Placenta samples were stored at $-80^{\circ} \mathrm{C}$ until analysed. Two to three random placentome samples from 12 (5 males) MIMT1 ${ }^{\text {DelWT }}$ (referred as IUGR) and 12 (3 males) MIMT1 ${ }^{\text {WTWT }}$ (wild-type) conceptus were used for small RNA next 
generation sequencing and quantitative real-time reverse transcriptase polymerase chain

2 reaction (qPCR).

\section{$3 \quad 2.3 \quad R N A$ extraction}

$420 \mathrm{mg}$ of tissue samples was used for total RNA extraction using Zymo Direct-zol RNA 5 MiniPrep kit (Zymo Research) according to the manufacturer's protocol. The quality and quantity of isolated total RNA was measured using a Nanodrop 2000 spectrophotometer (Thermo Fisher Scientific) and the fraction of small RNAs was examined on a 2100

\subsection{Small RNA next generation sequencing (NGS)}

Small RNA NGS was performed using a TruSeq Small RNA Library Prep Kit (Illumina), as previously described [14]. The Galaxy server was used for bioinformatic analyses. KEGG pathway (Kyoto Encyclopedia of Genes and Genomes) and mRNA : miRNA interaction analyses were performed using DIANA-miRPath v3.0 and TarBase v.7.0 software [14].

\subsection{Quantitative real-time PCR ( $q P C R)$}

qPCR was performed as described earlier [14]. Relative miRNA expression differences were normalised to endogenous miR-99b control. Data from IUGR and wild-type samples were compared by Students t test.

\section{Results and discussion}

miRNA profiling of foetal and maternal placental tissues using small RNA NGS revealed 48 foetal and 22 maternal miRNAs that were differentially expressed (FDR $<0.1$ ) in IUGR versus normal pregnancies, Figure 1. The male and female conceptus differ in placenta structure [15]. Our analysis did not reveal a significant conceptus sex effect, possibly due to the low number of samples analysed. To identify possible roles in early development, we performed functional enrichment analysis based on their target mRNAs. The pathways most significantly enriched $(P<0.0001)$ were related to 'oocyte meiosis', 'Wnt signalling pathway' and 'Dorso-ventral axis formation'.

Seven differentially expressed miRNAs were validated by qRT-PCR: miR-29a, miR-92b, miR-125b, miR-7641, miR-4321, miR-let-7g and miR-2895. These were selected on the basis of ranking in the list of differentially expressed miRNAs and predicted functional relevance for foetal growth and development. qPCR data confirmed differential expression of miR-4321 and miR-2895, with miR-4321 showing the greatest difference at 3.8-fold $(P<$ 0.01) lower expression in IUGR than wild-type maternal placenta, Figure 2. Interestingly, 
miR-432 displayed the opposite pattern of expression level in foetal placenta of IUGR, Figure 2. The other five miRNAs were not differentially expressed. Reasons for this discrepancy could include the heterocellular nature of placenta and differences in the sensitivity of the techniques.

miR-4321 has been reported to regulate several target genes involved in foetal growth and development. These include TRO (trophinin), which mediates adhesion of trophoblastic cells and epithelial cells of the endometrium and participates in cell adhesion during embryo implantation [16]. Others include STOX1 and DYRK1A, mutations of which are associated with pre-eclampsia with foetal growth retardation [17]. Possibly the most important miR-4321 target is PTGER3 (prostaglandin E receptor 3), which is mainly expressed in extravillous trophoblast of human placenta and involved in trophoblast invasion and placentation. Increased PTGER3 expression has been observed in recurrent pregnancy loss in humans [18] and in IUGR rats [19]. It is noteworthy that none of these genes were identified as differentially expressed in our earlier study [7].

Thus, accurate measurement of placental miR-4321 expression may be a biomarker for detection of pregnancies in risk. However, this would require robust and reliable means of distinguishing maternal and foetal placental cells, as each may respond differently to foetal genotype.

\section{Acknowledgments}

This study was financially supported by National Science Centre, Poland, project no. 2013/09/B/NZ9/03160 and 2016/23/N/NZ9/00232. The next generation sequencing data has been deposited in Gene Expression Omnibus (GEO) under accession number GSE118510. We thank Dr. A. Kind for critical reading of our manuscript.

\section{Figure legends}

Figure 1. Heatmaps showing the top differentially expressed miRNAs in foetal (a) and maternal (b) placental tissues of wild-type and IUGR bovine foetuses. The expression data are presented based on the normalised Log2-transformed fold change values and the $P$ value. $m$ - male, $f-$ female conceptus. 
1 Figure 2. Relative miRNA expression in a) placenta fetalis and b) placenta materna of wild-

2 type $(n=12)$ and IUGR $(n=12)$ bovine foetuses. Values are means and standard deviations

3 normalised to miR-99b. ${ }^{*} P<0.05$, ${ }^{* *} P<0.01$.

\section{$5 \quad$ Supporting information}

Table S1. List of qPCR primers.

Table S2. Differentially expressed miRNAs in maternal and foetal placenta tissues of IUGR bovine foetuses.

\section{References}

[1] W.M. Curtin, K.A. Millington, T.O. Ibekwe, S.H. Ural, Suspected Fetal Growth Restriction at 37 Weeks: A Comparison of Doppler and Placental Pathology, BioMed research international 2017 (2017) 3723879.

[2] A.C. Kelly, C.A. Bidwell, F.M. McCarthy, D.J. Taska, M.J. Anderson, L.E. Camacho, S.W. Limesand, RNA Sequencing Exposes Adaptive and Immune Responses to Intrauterine Growth Restriction in Fetal Sheep Islets, Endocrinology 158(4) (2017) 743755.

[3] I.M. Bernstein, J.D. Horbar, G.J. Badger, A. Ohlsson, A. Golan, Morbidity and mortalityamong very-low-birth-weight neonates with intrauterine growth restriction. The Vermont Oxford Network, American journal of obstetrics and gynecology 182(1 Pt 1) (2000) 198-206.

[4] R.A. Salam, J.K. Das, Z.A. Bhutta, Impact of intrauterine growth restriction on long-term health, Current opinion in clinical nutrition and metabolic care 17(3) (2014) 249-54.

[5] M. Pavlicev, G.P. Wagner, A.R. Chavan, K. Owens, J. Maziarz, C. Dunn-Fletcher, S.G. Kallapur, L. Muglia, H. Jones, Single-cell transcriptomics of the human placenta: inferring the cell communication network of the maternal-fetal interface, Genome research 27(3) (2017) 349-361.

[6] K. Flisikowski, H. Venhoranta, J. Nowacka-Woszuk, S.D. McKay, A. Flyckt, J. Taponen, R. Schnabel, H. Schwarzenbacher, I. Szczerbal, H. Lohi, R. Fries, J.F. Taylor, M. Switonski, M. Andersson, A novel mutation in the maternally imprinted PEG3 domain results in a loss of MIMT1 expression and causes abortions and stillbirths in cattle (Bos taurus), PloS one 5(11) (2010) e15116.

[7] H. Xu, H. Pausch, H. Venhoranta, K. Rutkowska, C. Wurmser, B. Rieblinger, T. Flisikowska, D. Frishman, L. Zwierzchowski, R. Fries, M. Andersson, A. Kind, A. Schnieke, K. Flisikowski, Maternal placenta modulates a deleterious fetal mutation, Biology of reproduction 97(2) (2017) 249-257. 
[8] D.M. Chadly, J. Best, C. Ran, M. Bruska, W. Wozniak, B. Kempisty, M. Schwartz, B. LaFleur, B.J. Kerns, J.A. Kessler, A.J. Matsuoka, Developmental profiling of microRNAs in the human embryonic inner ear, PloS one 13(1) (2018) e0191452.

[9] J. Mineno, S. Okamoto, T. Ando, M. Sato, H. Chono, H. Izu, M. Takayama, K. Asada, O. Mirochnitchenko, M. Inouye, I. Kato, The expression profile of microRNAs in mouse embryos, Nucleic acids research 34(6) (2006) 1765-71.

[10] E. Mondou, I. Dufort, M. Gohin, E. Fournier, M.A. Sirard, Analysis of microRNAs and their precursors in bovine early embryonic development, Molecular human reproduction 18(9) (2012) 425-34.

[11] A. Lycoudi, D. Mavreli, A. Mavrou, N. Papantoniou, A. Kolialexi, miRNAs in pregnancyrelated complications, Expert review of molecular diagnostics 15(8) (2015) 999-1010.

[12] P. Dravet-Gounot, C. Morin, S. Jacques, F. Dumont, F. Ely-Marius, D. Vaiman, P.H. Jarreau, C. Mehats, E. Zana-Taieb, Lung microRNA deregulation associated with impaired alveolarization in rats after intrauterine growth restriction, PloS one 12(12) (2017) e0190445.

[13] Q. Tang, W. Wu, X. Xu, L. Huang, Q. Gao, H. Chen, H. Sun, Y. Xia, J. Sha, X. Wang, D. Chen, Q. Xu, miR-141 contributes to fetal growth restriction by regulating PLAG1 expression, PloS one 8(3) (2013) e58737.

[14] M. Stachowiak, T. Flisikowska, S. Bauersachs, C. Perleberg, H. Pausch, M. Switonski, A. Kind, D. Saur, A. Schnieke, K. Flisikowski, Altered microRNA profiles during early colon adenoma progression in a porcine model of familial adenomatous polyposis, Oncotarget 8(56) (2017) 96154-96160.

[15] J.I. Kalisch-Smith, D.G. Simmons, H. Dickinson, K.M. Moritz, Review: Sexual dimorphism in the formation, function and adaptation of the placenta, Placenta 54 (2017) 10-16.

[16] N. Suzuki, J. Nakayama, I.M. Shih, D. Aoki, S. Nozawa, M.N. Fukuda, Expression of trophinin, tastin, and bystin by trophoblast and endometrial cells in human placenta, Biology of reproduction 60(3) (1999) 621-7.

[17] M. van Dijk, C.B. Oudejans, STOX1: Key player in trophoblast dysfunction underlying early onset preeclampsia with growth retardation, Journal of pregnancy 2011 (2011) 521826.

[18] Y. Ye, A. Vattai, N. Ditsch, C. Kuhn, M. Rahmeh, S. Mahner, M. Ripphahn, R. Immler, M. Sperandio, U. Jeschke, V. von Schonfeldt, Prostaglandin E2 receptor 3 signaling is induced in placentas with unexplained recurrent pregnancy losses, Endocrine connections 7(5) (2018) 749-761.

[19] K. Yamazaki, T. Endo, Y. Kitajima, K. Manase, K. Nagasawa, H. Honnma, T. Hayashi, R. Kudo, T. Saito, Elevation of both cyclooxygenase-2 and prostaglandin E2 receptor EP3 expressions in rat placenta after uterine artery ischemia-reperfusion, Placenta 27(4-5) (2006) 395-401. 
A

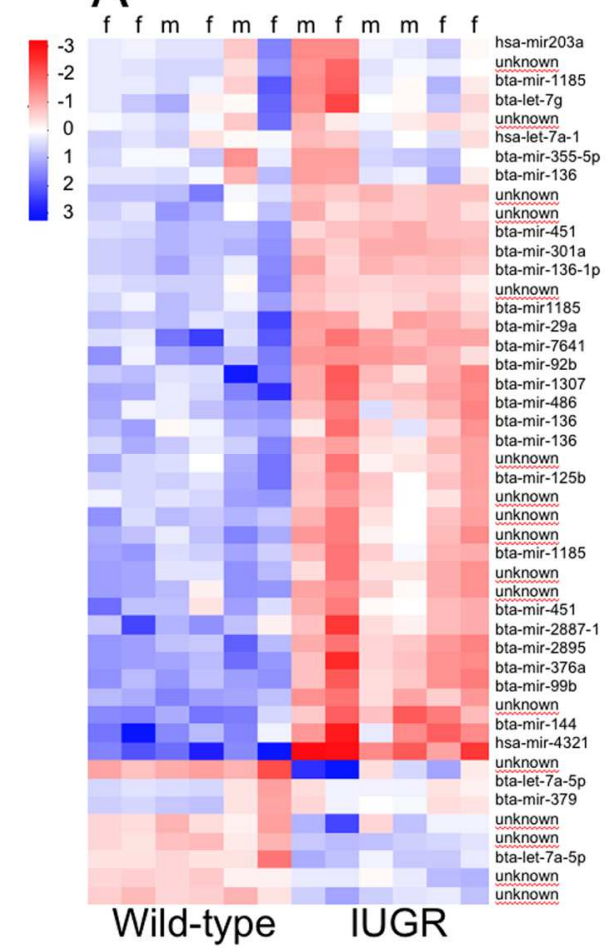

B

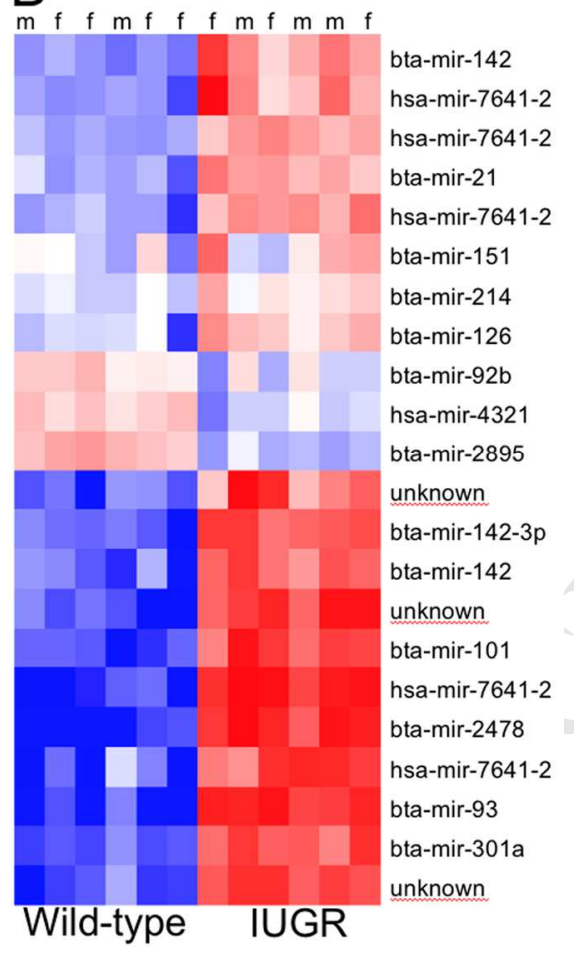



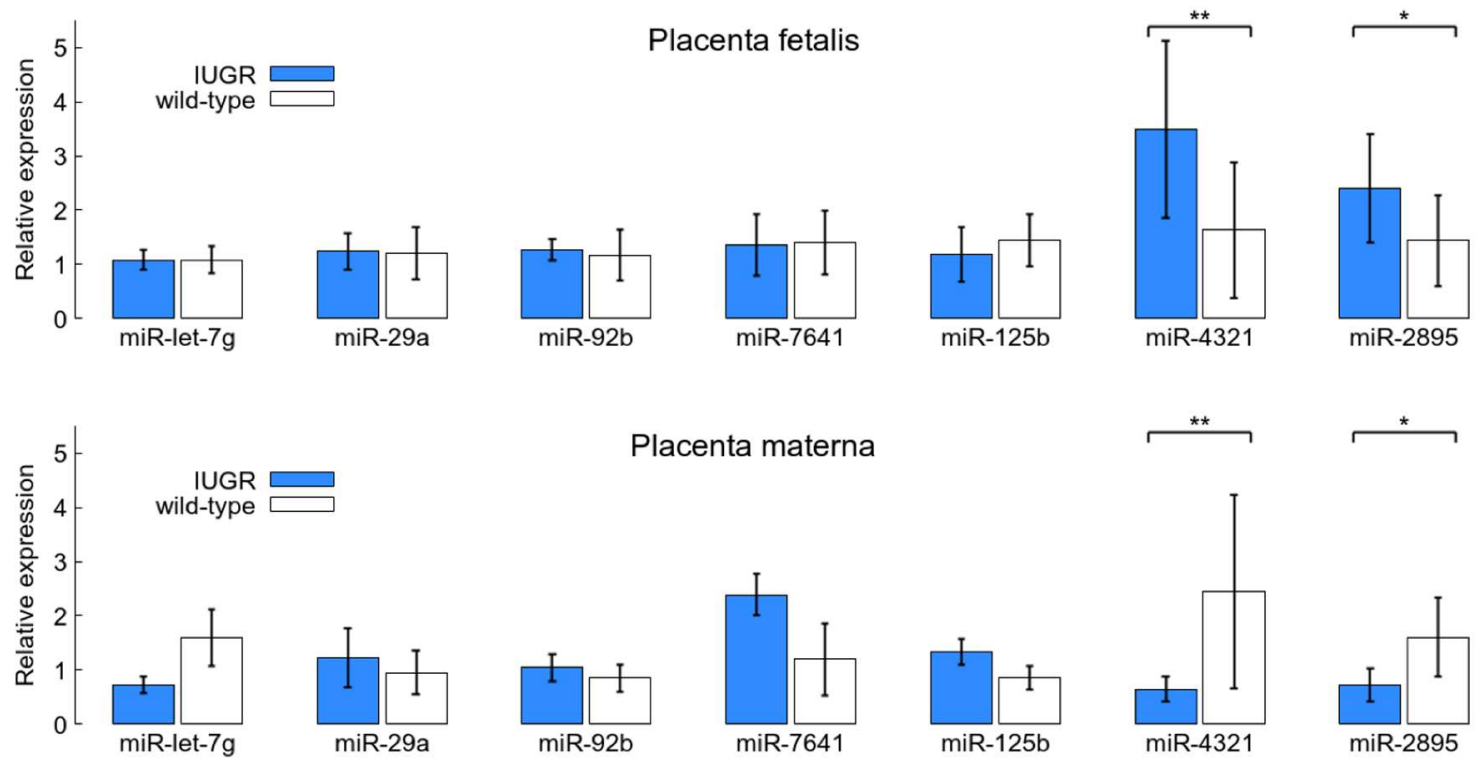

Placenta materna
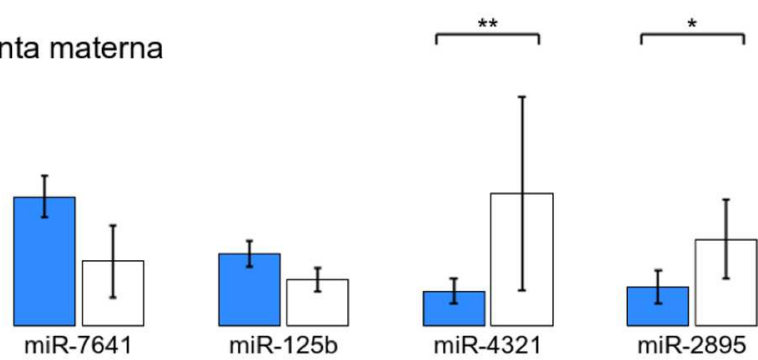


\section{Highlights}

- Aberrant expression of miR-4321 in bovine IUGR placenta.

- MiR-4321 regulate genes involved in early foetal development.

- Placental fetalis and materna respond differently to conceptus genotype. 